\title{
Digital Community Biomass Power Plant Competitiveness in Thailand
}

\author{
Suwannee Adsavakulchai ${ }^{1, *}$, Udomsak Kaewsiri ${ }^{2}$ \\ ${ }^{1}$ Computer Engineering and Financial Technology Department, University of the Thai Chamber of Commerce (UTCC), Bangkok, \\ Thailand \\ ${ }^{2}$ Computer Engineering and Financial Technology Department, University of the Thai Chamber of Commerce (UTCC), Bangkok, \\ Thailand
}

\begin{abstract}
The participation of citizens and communities as partners in energy projects are transforming the energy system. Community enterprise initiatives are offering new opportunities for local residence to get actively involved in energy matters. Meanwhile, the worldwide deployment of digital technology in energy sector has become a trending subject of sorts among industry giants as well as the start-up investor community, with applications ranging from grid transactions, financing and transparency in supply chain. This paper reviewed the community biomass power plants sector to comply with the resolution of the National Energy Policy Council, rules and regulations based on a Porter's Diamond model. The results show that such collaborations between local residents and private sector or private sector with state organisation can lead to win-win situations, digitalizing the community biomass power plant by connect all relevant sectors through digital platform and sophisticated innovation in particular Fintech and IT have important potential implications for the implementation of a range of sustainable development and enhancing security and efficiency of the power plant. It is considered to be of great importance in order to enhances competitiveness and will continue to be supported by the government.
\end{abstract}

\section{Introduction}

Thailand has issued a new regulation setting out criteria and conditions for power purchase agreements (PPAs) for very small power producers (VSPPs) under the Community Power Plants for the Local Economy project. The Regulation Procurement of Electricity from Very Small Power Producers was issued on April 2, 2020, by the Energy Regulatory Commission (ERC) and published in the Government Gazette on April 10, 2020 [1]. Community power plant project is considered one of the important strategic policies to not only build sustainability in energy consumption across communities and nearby area, but also to generate extra income for local residents. [2]. The use of biomass from community alone, however, may create a restriction of a power plant to be invested. Therefore, using biomass from both farms and agricultural processing plants, plus establishing a joint venture between local residents, entrepreneur and government organisation may be a viable guideline to allow operators to meet their business goals. At the same time, the convergence of digital and physical innovations, together with advances in energy technologies, has begun to impact the industry. These advances help open the way for digitalisation flows in the system, for realtime information, for a smarter combination of energy supply chain as well as enhanced performance from future investment collaboration.
Thus, this paper reviews the community biomass power plants sector to comply with the resolution of the National Energy Policy Council, rules and regulations have been determined by using Porter's diamond model and analyzing the operation of the joint venture of local communities which have the potential to establish their own power plants with private sectors under the government policy. Furthermore, the reviews of an emerging digital technology that has drawn considerable interest from supply firms, startups, technology developers, financial institutions, and governments. As such, the finding could be strategically important to the sustainable development of the country with the private sector and community to participate in the generation business could be in order to promote the sustainability of community biomass power plant in energy industry.

\section{Related Work}

This section summaries research activities in the field of digital community biomass power plant, analyse about the biomass, energy communities, digital technology and the state of the Regulations of the Energy Regulatory Commission on power procurement from very small power producers for the Community Power Plant Project for the Local Economy 2020 in Thailand. 


\subsection{Biomass for fuel}

The production of biomass is expected to grow significantly It is important to develop suitable crops to be used as biomass feedstock. Promoting plantation of fast growing trees can be used as feedstock for power/heat generation such as bamboo as energy crops due to its fuel characteristics, high productivity, and short rotation. [3] Furthermore, the feasibility of Biomass power plant with agricultural waste processing revealed that agricultural waste is fast becoming a crucial fuel source to meet increasing energy demand. The conversion of agricultural waste into electric energy seems to be inevitable in countries like India to meet the renewable energy goals. Presently, these resources are not exploited significantly due to a number of challenges. Major challenge is collection and densification of agricultural biomass. [4]

\subsection{Energy Community}

Energy communities are associations of producers and consumers of energy set up to reduce the dependence on fossil fuels and optimize the use of energy for the advantage of the members. Angelo Tartaglia [5] presents an experiment being implemented in the territory around the town of Pinerolo in western Piedmont. An energy community may involve various types of organisation, but all somehow interested in using energy. Its members may be private individuals, firms, or public administrations, but energy is the connecting motivation for all. There are well known examples: cooperatives of energy producers existing throughout Europe for commercial purposes, including in Italy; there are also cooperatives of consumers interested in buying energy under the best possible market conditions; and finally, there are associations doing both jobs. Of course, a reliable business plan must also be prepared. The community should have a positive balance sheet and, although regional law poses as a condition for its recognition that it be no-profit, its capacity to support itself is an essential requirement to ensure the long life of the institution.

\subsection{Digitalisation in the Energy Sector}

Currently, Industry 4.0 is developing based on mass digitalization, which is shaped by internet technologies and its come to fore and are shaping the future of the industry and natural society. [6] Prominent technologies which is focused in this paper will be explained below:

Blockchain: is a decentralized trustless proof mechanism of all the transactions on the network. It is a system of the public ledger which allows disintermediation and decentralization of all transactions between parties all around the world at the same time. [7]

Artificial Intelligence (AI): is the simulation of human intelligence processes by machines, especially computer systems. AI works by combining large amounts of data with fast, iterative processing and intelligent algorithms, allowing the software to learn automatically from patterns or features in the data. [8]

Big Data Analytic: refers to the process of collecting, organizing, analyzing large data sets to discover different patterns and other useful information. Big data analytics is a set of technologies and techniques that require new forms of integration to disclose large hidden values from large datasets that are different from the usual ones, more complex, and of a large enormous scale. It mainly focuses on solving new problems or old problems in better and effective ways. [9]

Cloud Computing/Technology: is the delivery of different services through the Internet. These resources include tools and applications like data storage, servers, databases, networking, and software. is a popular option for people and businesses for a number of reasons including cost savings, increased productivity, speed and efficiency, performance, and security. [10]

Digital innovations have already begun to transform the energy industry. They help open the way for multidirectional energy flows in the grid, for real-time demand adjustment in response to supply conditions, for a smarter combination of different energy supply sources and more. Together, these changes brought about through digital innovation will increase the efficiency, affordability, reliability, and sustainability of the system. However, the penetration of digital technology adoption however is limited. Operational challenges of sustained profitability, data deluge and an aging workforce still remain significant. [11]

Anak Agung Gde Agung and Rini Handayani [12] presents how a blockchain implemented to manage transactions in the smart grid, which consists of electricity generators, consumers and nodes which can do both. An architecture is proposed, and a mobile application is developed as an inter- face between users and the system. The integration of blockchain into the smart grid allows the community to maintain transactions in the system in a consensus manner. Transactions are performed with smart contracts. Transaction history is stored in the blockchain and duplicated to all full nodes. The blockchain provides immutability to the smart con- tracts and transaction data, by restricting a record to be changed or erased. Therefore, a smart contract between a generator and a consumer will always be executed, providing certainty that a pro- ducer will always deliver the electricity when a consumer has paid. The immutability also provides traceability, which is good for audit or solving a transaction dispute. The Ethereum blockchain runs on Proof of Work consensus mechanism, so transactions are verified by miners around the world, including nodes running the full node.

\subsection{The Regulations of the Energy Regulatory Commission on power procurement from very}




\section{small power producers for the Community Power Plant Project for the Local Economy 2020}

The council allows the private sector or private sector and state organisation to form joint ventures with community enterprises at least 200 households to operate renewable power projects in remote areas. Private sector can invest in the Energy for all scheme, and a state organisation is allowed to invest in community-owned power projects, while communities can hold shares ranging from $10-40 \%$ (10\% preferred stock and up to $40 \%$ in additional stock). The Executive Committee of Power Purchase from Community Power Plant Projects will use a Feed-in Tariff (FiT) mechanism in renewable power investment for Very Small Power Producers (VSPP), with $10 \mathrm{MW}$ for non-firm power plant and the government will start buying $700 \mathrm{MW}$ from private producers. The private sector must implement a profit sharing scheme whereby revenue from the sale of electricity, before deduction of expenses, has to be distributed to the local communities' fund and will also be required to enter into a resources purchase agreement, in a form of 'Contract Farming', with the local communities to ensure the quantity, quality and price of the resources to be supplied by the local communities. [13]

\section{Methodology}

Theoretical Framework for the Digital Community Biomass Power Plant based on Porter's Diamond Model [14] and research propositions. The Diamond Model focuses on the cooperation significance of all relevant sectors. Our purpose is to obtain an approach to the new collaboration together between the digital power plants and the community, it can be done together in a sustainable manner leading to the efficient and sustainable use of energy, creating a stronger community network and ensuring energy commercial significance and driving digital transformations across energy industry.

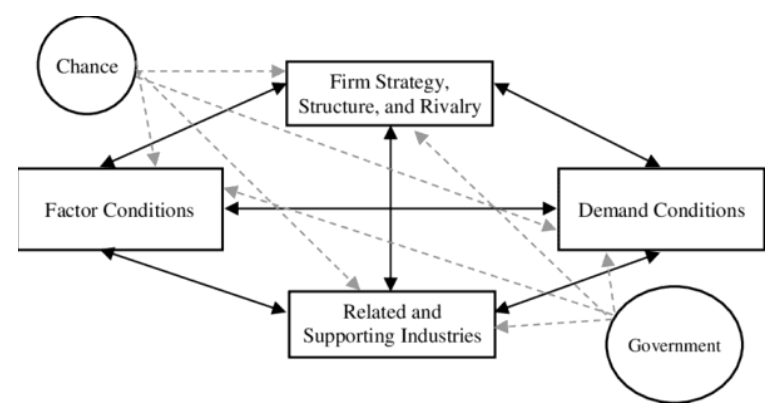

Fig. 1. Michael Porter Diamond Model

\section{Discussion}

This research aims to comprehensively analyse factors that have significant influences on it using a diamond model, which is a widely recognized model for analysing competitiveness of nations and focuses on Regulations of the Energy Regulatory Commission on power procurement from very small power producers for the Community Power Plant Project for the Local Economy 2020 in Thailand which has been an important development under conditions of collaborative and deliberative cooperation with private sector, governmental, and community enterprise where digital solutions can have the greatest impact efficiency and reliability.

\subsection{Government}

The Government of Thailand has long recognised the importance of alternative energy, especially renewable, energy sources, also realised that there was a need to introduce programmes in support of community power plant development. With that, a variety of support programmes have been put in place to promote renewable energy development, ranging from tax exemptions, a feed-in premium (FIP)/adder programme and FITs to competitive bidding, to address the various challenges that renewable energy projects face in the early stage of development. Also the entering into purchase contracts with local farmers for 20 years for energy crops. This policy will help increase income and stimulate the economy at the local level. Furthermore, under the supervision of the Digital Economy Promotion Agency, focusing on excellence in promoting digital startup to be an important mechanism in developing and driving the country towards digital economy and entrepreneurial economy.

\subsection{Factor Conditions}

\subsubsection{Natural Resources}

The cultivation of energy crops that can be used as feedstock for power/heat generation will be the solution for all sectors. However, the response of local farmers to energy crop cultivation is initially rather limited due to lack of incentives. So far energy crops have very little presentation in potential areas. Replacing crops with fast-growing tree so far is agronomically possible due to the growing needs of power plant for biomass crops. The cultivation of fast-growing tree such as bamboo, Acacia mangium, or Napier grass could contribute to the innovation of agricultural production with multiple benefits for the farmers, the economy and the environment and the farmers should take seriously under consideration to cultivate energy crops as alternative in order to improve their income. Moreover, the community biomass power plant processes are complex, nonlinear and dynamic which behave differently depending upon variations in the operating and ambient conditions, thus posing significant challenges to maintain the efficiency of the power plant through datadriven modeling and optimization using Artificial Intelligence (AI) techniques can be better achieved moisture diagnosis of biomass fuel resulting in the realtime heat rate improvement through an effective plant operation. 


\subsubsection{Capital Resources}

Power plant development is highly capital intensive and requires significant capital investment by project developers. Lack of funding options by community usually, power projects also involve extensive debt financing. To drive consistent progress of the project towards its goal, the community enterprise could be supported capital by Bank for Agriculture and Agricultural Cooperatives (BAAC) and emerging platform of crowdfunding as an alternative financial method as well. The development of crowdfunding with blockchain, the power plant is also obtaining the potential to optimize energy management processes in almost all stages of the value chain and at the same time to cope with the growing complexity in the increasingly decentralized energy system. A blockchain-based electricity marketplace cannot only match the demand and supply side for energy purchases, but also immediately settle the transactions for community enterprise both energy crops selling and return on equity, including monitoring the delivery of electricity and processing of corresponding payments and that would open up considerable positive consequences. Trading based on blockchains would allow and also the possibility of incentivizing the equity crowdfunding and easily accessing the capital resources.

\subsubsection{Technological and Innovation}

In digital community biomass power plant upgrades will be required by investment smart management and control need to be adopted, tasks that are increasingly challenging as energy systems are growing to become more active, decentralised, complex and 'multi-agent', with an increasing number of sectors and possible actions. Advanced communication and data exchanges between different parts of the power network are to an increasing extent required, making central management and operation more and more challenging. The emergence of innovative digital financial technologies (FinTech), namely blockchain and crowdfunding, indicates new ways to increase in transparency of company infrastructure and of operations. The using of blockchain to share and distribute data structures or ledgers can securely store digital transactions without using a central point of authority. These also provides an overview of the current status of energy crops cultivation from community enterprise through satellite technologies available for agricultural sector. This should look to help yields, stability, crop management and monitoring of current conditions, density and also make accurate future predictions. [15] At the same time, digital community biomass power plant project can be a challenge, considering that capital costs are high. The emerging finance method of "crowdfunding" for renewable energy has become quite successful in the last few years. Many platforms are available to manage such projects and communicate with the participants. This is a new way to eliminate third parties, provide energy and monetary benefits to investors and democratize energy in the truest sense. In addition, using of artificial intelligence (AI) and Big data are seen as revolution in achieving the future goals of renewable energy which becomes more and more important in the energy industry and is having great potential for the future design of the energy system. AI helps make the energy industry more efficient and secure by analyzing and evaluating the data volumes as well as efficient operations management, workflow and portfolio management for all sectors.

\subsection{Demand Conditions}

The Private power generation business will see growth in business through 2019-2021, with electricity demand forecast to rise by an average of 3-3.5\% per year. Thailand's electricity generating sector is considered to be one of the most secure businesses in Thailand for private operators given the long-term power purchase agreement with the state utilities PEA. In terms of the situation of renewable energy business, in 2018, there was a total of 937 SPP and VSPP projects (including projects that received support under the adder and FiT systems) selling electricity to the national grid and these had a contracted capacity of 4,877 MW. However, biomass generation has begun to experience problems over competition for inputs and from local communities objecting to the siting of biomass electricity generating plants nearby and this has led to a large number of operators cancelling their contracts to supply Electricity Generating Authority of Thailand (EGAT). In addition, some players are waiting to transition from the adder to the FiT system. [16]

\subsection{Related and Support Industries}

From the prospect of digital community-based biomass power plant, the entrepreneur is directly responsible for managing its suppliers, and this should be significant consider. The rise and development of FinTech in energy sector makes it meaningful for all suppliers as a trusted business partner. Using of blockchain will assist not only the EPC (Engineering-ProcurementConstruction) and the effective Operation \& Maintenance (O\&M) suppliers in the diagnosis, management and prediction of cash flows to mitigate the rate of their business failure but also the insurance companies will enables automated real-time data collection and analysis, potentially making some types of claims process faster and can greatly speed up claims processing and payouts.

\subsection{Firm Strategy, Structure and Rivalry}

Many energy projects are costly, complex and often too risky for one party to handle alone. A joint venture structure can serve as an optimal solution by effectively spreading an energy project's risk and expense and providing resources and capabilities to deal with inherent complexities. Joint ventures in the energy industry can be highly effective tools for creating greater value for 
each of the parties involved, provided those relationships are structured and managed properly through innovations in new financial technologies (FinTech) which is one of the significance strategies. As a result, blockchain technology has been described as a trust machine because it produces the efficiencies of trust between parties without a central intermediary. This interrelationship between all technological strategy will enable a future potential community power plant and will create new possibilities for the fulfillment of sustainability goals where these digital technologies are developed.

\subsection{Chance}

The sustained availability of feedstock is one of the biggest risks to any biomass project. Agreeing of long term volume and price contracts will give certainty to both the entrepreneur and to the community enterprise. Or even, rapidly growing technology, which means that the technology you invest in today may seem to be outof-date almost the moment it is installed and up and running. Keeps the power plant current with the latest trends. But it's also a sizable outlay of capital, not only for the technology itself, but for the revamping of related systems. Employees need to be trained on new systems, technical staff needs to update its certifications and capabilities have to be revised. Lastly, the power plant might face resistance from communities. All relevant sectors should pay more attention to the community and ensuring the participation and approval of the local community is essential.

\section{Conclusion}

The analysis reflects that the operation of digital biomass power plant from community alone may create a restriction in terms of the size of a power plant, capital access and know-how to be invested and this has discouraged in many aspects. Therefore, under Regulations of the Energy Regulatory Commission 2020 the using biomass from the community enterprise, plus establishing a joint venture between local residents and private sector or private sector with state organisation raises new challenges in management and operation of power plant systems on the brink of entering the digital era. Financial technologies (FinTech) are playing a vital role in providing greater financial access to the financially underserved populations. In particular, the growing use of crowdfunding platforms and blockchain has created new means to reach financially constrained individuals, households and companies as well as enables the development of innovative solutions that can maximize the potential of decentralized energy access arrangements for households. The Big Data is also applied to store all data systematically which can be accessed efficiently by using Artificial Intelligence (AI) to analyze and process operations together with being the complete power system control to enable high efficiency and availability of the power plants. The community power plant with high efficiency and accuracy, controlled and dispatched by digital system could be applied in the energy trading platform particularly blockchain-enabled methods of energy trading for community. These digital technologies will reimagine the entire energy system -how power is distributed, managed, traded, used and governed. It will empower private sector and community enterprise to easily manage and share their data. The greater transparency and accountability by using digital technology will help build trust and credibility with the local communities, governments and other stakeholders which will be a key success factor and maximise the chances of sustaining operation of digital community biomass power plant project over the long term. This may be a viable guideline to allow operators to meet their business goals while responding to the purpose of a digital community power plant project.

\section{References}

1. Tanadee Pantumkomon, "Thailand Issues Regulations for Procurement of Electricity from Very Small Power Plants., in press.

2. Ministry of Energy, "Regulations of the Energy Regulatory Commission on power procurement from very small power producers for the Community Power Plant Project for the Local Economy 2020”, 2020.

3. Roshan Sharma, Jaya Wahono and Himlal Baral, "Bamboo as an alternative bioenergy crop and powerful ally for Land Restoration in Indonesia", 2018.

4. Anil Gojiya and Dipankar Deb, “On feasibility of Biomass Power Plant with Agricultural Waste Processing", 2017, in press.

5. Angelo Tartaglia, "Energy Communities." E3S Web of Conferences 119, 00015 (2019).

6. Noor Hazlina Ahmad, Qaisar Iqbal and Hasliza Abdul Halim, "Challenges and Opportunities for SMEs in Industry 4.0”, 2020.

7. Melanie Swan, "Blockchain: Blueprint for a new economy", 2015.

8. Donesafe, "What Is The Difference Between Artificial Intelligence And Machine Learning?", 2018, in press.

9. Jai Prakash Verma, Smita Agrawal, Bankim Patel and Atul Patel, "Big Data Analytics: Challenges and applications for text, audio, video, and social media data", 2016.

10. Jake Frankenfield, "Cloud Computing", 2020, in press.

11. Marco Annunziata, Ganesh Bell. "Powering the future: Leading the digital transformation of the power industry", 2015.

12. Anak Agung Gde Agung and Rini Handayani. "Blockchain for smart grid", 2020. 
13. Ministry of Energy, "Regulations of the Energy Regulatory Commission on power procurement from very small power producers for the Community Power Plant Project for the Local Economy 2020", 2020.

14. Porter, M.E., "The Competitive Advantage of Nations", Free Press, New York, 1990.

15. Dharmin Dave, Shalin Parikh, Reema Patel and Nishant Doshi, "A Survey on Blockchain Technology and its Proposed Solutions," 3rd International Workshop on Recent Advances on
Internet of Things: Technology and Application Approaches (IoT-T\&A 2019), pp. 740-745.

16. Narin Tunpaiboon, "Power Generation," Thailand Industry Outlook 2019-2021, 2019. 